\title{
IMPORTANCIA DEL MICROAMBIENTE TUMORAL EN LA PROGRESIÓN DEL CÁNCER DE MAMA
}

\section{IMPORTANCE OF TUMOR MICROENVIRONMENT IN BREAST CANCER PROGRESSION}

\section{RESUMEN}

\author{
Julio E. Valdivia-Silva ${ }^{\mathrm{a}}$, Eduardo García-Zepeda ${ }^{\mathrm{b}}$
}

\begin{abstract}
El microambiente tumoral, en el cáncer de mama y otros de estirpe epitelial, es un tejido complejo que comprende diferentes tipos celulares que incluyen las células tumorales, fibroblastos, células endoteliales, y leucocitos infiltrantes. Citocinas, quimiocinas, factores de crecimiento y proteasas son moléculas claves que controlan la comunicación autocrina y paracrina entre estas células individuales. Bajo algunas circunstancias, dichas moléculas pueden orquestar respuestas del hospedero contra el tumor, pero contradictoriamente existe evidencia que demuestra un rol paradójico que contribuye al crecimiento y progresión de la neoplasia además de inmunosupresión local. Adicionalmente, la progresión del cáncer de mama está asociada con una robusta neovascularización. Es claro que las células "normales" asociadas al tumor, como las inmunes, endoteliales y del estroma, conspiran con las cancerosas en promover este proceso. En ésta revisión enfocamos algunas de las acciones de citocinas inflamatorias y otras moléculas del microambiente tumoral sobre el comportamiento invasivo y metastásico del carcinoma mamario. Una mayor comprensión de estos tipos celulares y constituyentes moleculares del microambiente pueden ser usados en el diseño de terapias más efectivas contra el cáncer.
\end{abstract}

Palabras clave: cáncer de mama, microambiente tumoral, metástasis, inflamación

\begin{abstract}
The epithelial tumour microenvironment is a complex tissue comprising variable numbers of tumour cells, fibroblasts, endothelial cells and infiltrating leucocytes. Cytokines, chemokines, growth factors, and proteases are key molecules controlling autocrine or paracrine communications within and between these individual cell types. Under some circumstances, endogenous cytokines may orchestrate host responses against the tumour, but there is increasing evidence that the cytokine network contributes to tumour growth, progression and host immuno-suppression. In addition, breast cancer progression is associated with and dependent upon robust neovascularization. It is becoming clear that tumour-associated 'normal' cells, such as immune/inflammatory cells, endothelial cells and stromal cells, conspire with cancer cells in promoting this process. In this review we outline some of the actions of endogenous inflammatory cytokines and other molecules in tumor microenvironment over metastatic and invasive behavior of the breast carcinoma. A better understanding of these various cellular and molecular constituents of breast cancer microenvironment may be useful in designing more effective therapies.
\end{abstract}

Key words: breast cancer, tumour microenvironment, metastasis, inflammation.

\section{INTRODUCCIÓN}

El cáncer de mama es el segundo tipo de cáncer más común después del cáncer de cuello uterino en los países en vías de desarrollo y es el responsable de cerca de 40,000 muertes anualmente en los Estados Unidos [1]. La gran mayoría de estas muertes se deben principalmente a metástasis a órganos distantes, como pulmón, hueso, hígado y cerebro. Aunque los eventos moleculares que median los primeros pasos de este proceso en el órgano invadido han sido revisados exhaustivamente [2-4], todavía existen muchas interrogantes acerca del gatillo inicial que lleva a estas células a abandonar el tumor primario, la adquisición de esta nueva característica y acerca del destino final de invasión, el cual no es al azar [5].

La visión "reduccionista" del cáncer que lleva a pensar en el tumor como un conjunto de células transformadas que crecen, proliferan e invaden guiadas por su "fondo genético alterado" y que metastatizan debido a su afán de supervivencia [6], no permite entender claramente la progresión de la enfermedad. Es conocido pues, que existe una gran variabilidad durante la enfermedad inclusive en un mismo tipo de cáncer y que a pesar de usar la misma terapia la respuesta está sujeta a múltiples variables individuales tampoco bien comprendidas.

La aparición de metástasis atípicas también constituye un tema poco dilucidado y no explicado por el tipo de mutación de la célula cancerosa. Hace pocos años dicha concepción reduccionista ha sido modificada por una nueva visión más completa denominada "heterogénea". Este enfoque muestra a las células tumorales interaccionando constantemente con diferentes tipos celulares que incluyen células inflamatorias inmunes, endoteliales y estromales [6]., conceptuando un nuevo tejido nombrado como microambiente tumoral. La interacción de

la célula cancerosa con células del microambiente puede permitir en muchos casos respuestas paradójicas anti- o pro-tumorales que dependen de diversos factores también no dilucidados y contradictorios; sin embargo, se conoce que esta interacción con el microambiente puede

\footnotetext{
a Grupo de Investigación en Inmunología, Facultad de Medicina, Universidad N acional San Agustín de Arequipa, Perú.

b Departamento de Inmunología, Instituto de Investigaciones Biomédicas, Universidad Nacional Autónoma de México, México DF.
} 
potenciar o silenciar genes presentes en el tumor, llevando a diferentes comportamientos de las células tumorales a veces lejos del esperado por su estadiaje histopatológico.

La presencia de factores liberados en el microambiente tumoral por las diversas interacciones celulares ha mostrado tener una importancia en la evolución de la enfermedad; por ejemplo, Lin et al. demostró en un modelo murino de carcinoma mamario que cuando se expone el tumor al Factor Estimulante de Colonias de Monocitos-1 (CSF-1), un factor de crecimiento y quimioatrayente de monocitos sanguíneos durante la inflamación, el tumor era infiltrado por una gran cantidad células inflamatorias que disparaban al tumor a un comportamiento invasivo y metastásico, en comparación al tumor no estimulado que presentó etapas de cáncer in situ y una progresión lenta [7].

Concomitantemente, nuestro grupo ha demostrado que la línea celular humana MCF-7 de cáncer de mama, considerada poco invasiva por su perfil genético, cambió su comportamiento preestablecido a un fenotipo agresivo luego de estimularla con moléculas inflamatorias normalmente presentes en el microambiente tumoral [8].Dado que el microambiente tumoral depende directamente del tipo de respuesta ensamblado por el hospedero, esta revisión pretende mostrar brevemente la interacción de diversas células y moléculas del entorno del tumor que permita ayudar a comprender el rol paradójico pro-tumoral en lugar de una respuesta antitumoral que es la esperada. Aunque el punto de quiebre entre ambas respuestas opuestas todavía no está bien dilucidado, nosotros proponemos que el resultado final depende íntegramente del tipo de respuesta inmune de fondo que poseía el hospedero y su capacidad de cambio frente a diversos estímulos; un proceso que debe ser estudiado de inicio en la historia clínica de cada persona.

Finalmente, pretendemos mostrar la importancia del microambiente tumoral como un eje central que permita entender las fallas de la respuesta alrededor del tumor y como un punto de partida para modular la respuesta contra el tumor independientemente, en muchos casos, de la genética de fondo de la célula cancerosa [9]., que como se está demostrando es susceptible a cambio por el entorno.

\section{COMPONENTES DEL MICROAMBIENTE TUMORAL}

\section{1- CÉLULAS INFLAMATORIAS Y SUS REGULADORES MOLECULARES}

La infiltración de linfocitos, macrófagos, mastocitos y neutrófilos en diversos tejidos son marcas de procesos inflamatorios, defensa y reparación tisular, y también se encuentran presentes alrededor de cualquier tumor [10].. Por un lado, varios tipos de linfocitos infiltrados en el tumor que incluyen células $\mathrm{T}$ citotóxicas, células $\mathrm{NK}, \mathrm{y}$ células NK activadas por linfoquinas son considerados potencialmente anti-tumorales y pueden frenar el crecimiento del tumor [11]., pero por otro lado, macrófagos asociados al tumor (TAMs) que constituyen el mayor componente infiltrativo leucocitario y macrófagos activados han mostrado tener efectos contradictorios frente al tumor [12, 13].
Estudios clínicos han mostrado que la infiltración de células inflamatorias inmunes se relaciona con aumento en la densidad vascular y pobre pronóstico en varios tipos de cáncer, sugiriendo que estas células contribuyen en la progresión del tumor por estimular neovascularización [14].

La infiltración de células inmunes del hospedero en los tumores es regulada por las interacciones dentro del microambiente tumoral, en combinación con factores derivados directamente del tumor y el fondo inmune del hospedero.

En el cáncer de mama es conocido que existe una gran infiltración leucocitaria particularmente de TAMs guiada por diversos estímulos como hipoxia y que está relacionada con bajo pronóstico $[15,16]$.

En el cáncer de mama inflamatorio, la expresión constitutiva de la oncoproteina RhoC está asociada con una sobreexpresión del factor angiogénico VEGF (Factor de Crecimiento del Endotelio Vascular) y la citocina inflamatoria IL-6, que lleva a la formación de un estroma inflamatorio proangiogénico que es una forma agresiva de la enfermedad [17]. MCP-1 (Proteina quimiotrayente del monocito-1), un miembro de la familia de las quimiocinas C-C, está involucrada en la migración de monocitos y linfocitos al tumor activando concomitantemente células del estroma, lo que se correlaciona directamente con infiltración de TAMs y bajo pronóstico del cáncer de mama [18]

Otras moléculas secretadas por las células del microambiente tumoral y por el propio tumor como el factor estimulante de colonias -1 del macrófago (CSF-1) también han demostrado estar expresadas de manera abundante en los tumores mamarios y también se asocian a infiltración de TAMs y pobre pronóstico [19].

Curiosamente la producción transgénica de este factor CSF-1 por el hospedero, en un modelo murino de cáncer de mama, mostró gran infiltración de TAMs y progresión rápida de la enfermedad a estadios avanzados. En el mismo modelo murino donde el factor no era producido de manera constitutiva, el tumor no tuvo un importante infiltrado inflamatorio y la progresión a estados avanzados fue muy lenta [7]. Este hecho es vital para entender la importancia de la regulación que el microambiente "dependiente de la respuesta del hospedero" ejerce sobre el tumor "independientemente del fondo genético inicial de la célula cancerosa".

El reclutamiento de monocitos, macrófagos y otras células inflamatorias en el microambiente tumoral parece ser un denominador común en el desarrollo y progresión del tumor (Figura 1). Las células inflamatorias contribuyen en la angiogénesis y linfangiogénesis al brindar factores de crecimiento proangiogénico, citocinas y proteasas [20], que a su vez es un hecho determinante para la invasión y metástasis a órganos distantes.

Si se toma en cuenta la inhibición de células inflamatorias al tumor como terapia anticancerosa, es necesario recordar que también estas células ejercen efectos antitumorales; por ende es siempre necesario valorar cual es el error de la respuesta en cada caso. Probablemente el 
punto de quiebre entre ambos tipos de respuesta global frente al tumor no sólo dependa del tipo de neoplasia, sino del momento en que la respuesta es ensamblada, la intensidad y naturaleza de la respuesta, la cual finalmente se resume en el "fondo inmunológico previo del hospedero".

Es necesario recordar que el sistema inmune es dinámico y su efectividad depende de un "aprendizaje" constante desde tempranos momentos de la vida, un adecuado suministro de energía, y una constante interacción con otros sistemas psico-neuro-endocrinos, que complican el estatus final de respuesta.

Por tal motivo una exploración del microambiente puede darnos una guía adecuada de las falencias presentes en la respuesta y orientarnos por ejemplo en potenciar infiltración de linfocitos inhibiendo la de monocitos, o activando un tipo de respuesta $\mathrm{TH} 1$ o $\mathrm{TH} 2$ dependiendo sea el caso.

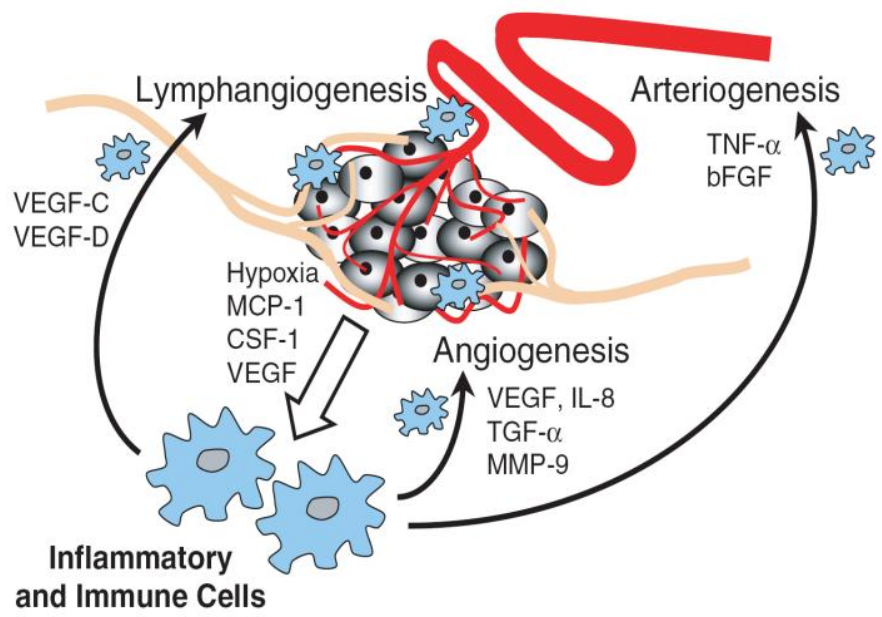

Figura 1. Las células inflamatorias son reclutadas por el microambiente tumoral y juegan roles durante la progresión del tumor promoviendo, en muchos casos, su expansión por estímulo de la angiogénesis y arteriogénesis que son esenciales para la metástasis. bFGF, factor básico de crecimiento de fibroblastos; CSF, factor estimulante de colonias; MCP, factor quimioatrayente de macrófagos; MMP, metaloproteinasas; TGF, factor de crecimiento transformante; TNF, factor de necrosis tumoral; VEGF, factor de crecimiento del endotelio vascular.

\section{2- CITOCINAS Y QUIMIOCINAS}

Las citocinas y quimiocinas comprenden una gran familia de moléculas comunicantes intracelulares que juegan importantes roles en inmunidad, inflamación y reparación, además de funciones homeostáticas. Las citocinas son claves en el control autocrino y paracrino entre células individuales del microambiente tumoral, promoviendo el crecimiento y sobrevivencia de células tumorales, dirigiendo el desarrollo y remodelamiento de la matriz extracelular, regulando el infiltrado linfocitario en el tumor, estimulando la neovascularización, manipulando la respuesta inmune y contribuyendo en varios pasos de la metástasis.

Bajo algunas condiciones, las citocinas endógenas pueden orquestar respuestas anti-tumorales, pero dependiendo de factores locales o sistémicos, la mayoría de veces existe una red inflamatoria disregulada que contribuye con el tumor. Esto es muy conocido dado que en estados controlados de inflamación existen frenos y mecanismos de regulación en las células, características perdidas en las células tumorales que además constituyen un tejido heterogéneo con zonas más 0 menos susceptibles (21).

Una de las citocinas más importantes en el microambiente tumoral es el TNF- $\alpha$ (Factor de necrosis tumoral- $\alpha$ ), que es un polipéptido que actúa biológicamente al unirse a dos receptores conocidos como p55 y p75, encontrados en una gran variedad de células de mamíferos (22). La inducción del TNF y sus receptores tiene diferentes efectos pro-apoptóticos y anti-apoptóticos, proliferativos e inductores de diversas moléculas que incluyen otras citocinas inflamatorias (23).

TNF ha sido detectado en células del estroma de cáncer de mama, próstata, vejiga y cólon asociado con otras citocinas como IL-1, IL-6 y CSF, producido principalmente por los TAMs $(24,25)$ y relacionado directamente a bajo pronóstico (26). Adicionalmente, en modelos animales se ha observado que la IL-1 promueve positivamente el desarrollo del tumor y junto con TNF son considerados factores de bajo pronóstico (27). Aunque, TNF también posee efectos anti-tumorales (28), sus acciones son paradójicas: en una mano su producción endógena crónica en el microambiente puede mostrar efectos protumorales al inducir citocinas y metaloproteinasas y ejercer efectos de daño al DNA por radicales libres; y en la otra es necesaria su producción para activar células CD8 y NK anti-tumorales, además que su administración en dosis altas destruye la vasculatura tumoral (24).

Nuevamente se observa una molécula inflamatoria con capacidades duales dependiendo del equilibrio global del microambiente.

Otras moléculas que han tomado gran importancia en la progresión tumoral y que son reguladas por el microambiente son las quimiocinas. Estas moléculas son péptidos pequeños que presentan una actividad quimiotrayente y que se clasifican de acuerdo a la posición de 2 aminoácidos de cisteína que les da su conformación espacial y actividad (C, CC, CXC, CXXXC donde $X$ es cualquier aminoácido). Las quimiocinas se unen a receptores acoplados a proteínas $G$ y ejercen múltiples funciones en el control del tráfico leucocitario en homeostasis y enfermedad, durante el desarrollo de los órganos linfoides para una estructuración y compartamentalización adecuada y durante procesos como angiogenesis, supervivencia y apoptosis (29).

La presencia de macrófagos y linfocitos en tumores sólidos está relacionada a la producción de quimiocinas por el tumor y su microambiente, como las quimiocinas CC en el cáncer de mama y cérvix (30). Quimiocinas como CCL2, CCL3, CCL4 y CCL5 se han observado en diversos tumores epiteliales y su expresión se correlaciona con mayor infiltración de células inflamatorias (31) que dependiendo de su tipo e intensidad de producción atraen linfocitos o macrófagos de manera diferente.

El balance macrófago/linfocito en el microambiente parece jugar un rol crítico en el desarrollo del cáncer 
como hemos estado evaluando hasta ahora, cosa que podría ser regulada por la manipulación de la red de quimiocinas, buscando un equilibrio que lleve al rechazo del tumor. Por ejemplo, la sobreexpresión de CCL20 suprimió el crecimiento de un tumor experimental luego de atraer células dendríticas y linfocitos T citotóxicos (32); igualmente CCL19 ocasionó eliminación de un carcinoma mamario murino al incrementar el infiltrado celular de NK y linfocitos CD4 (33).

De manera inversa, las quimiocinas de la familia CXC han mostrado efectos pro-tumorales induciendo angiogénesis, linfangiogénesis o promoviendo la sobrevivencia de las células cancerosas $(33,34)$.

Otra función muy importante atribuida a las quimiocinas y sus receptores es la relación directa con el homing metastásico. La migración directa de células tumorales a órganos distantes por vía sanguínea o linfática mediada por receptores de quimiocinas expresadas por las células tumorales, ha llevado a resolver una serie de interrogantes acerca de la selectividad de varios tipos de cáncer por ciertos órganos. Numerosos estudios han demostrado la expresión basal de ciertos patrones de receptores de quimiocinas que responderían a gradientes de sus ligandos respectivos liberados por el órgano blanco a ser invadido (5). De 16 receptores de quimiocinas investigadas en varias líneas celulares de cáncer de mama, los receptores CXCR4 y CCR7 fueron encontrados que tenían una expresión importante en las líneas celulares consideradas más agresivas (5). Curiosamente sus ligandos CXCL12 y CCL19 respectivamente, se encontraron expresados en los órganos más frecuentes de metástasis para el cáncer de mama. Estudios posteriores han mostrado diversos patrones de receptores de quimiocinas en diferentes tipos de cáncer (35).

Aunque estos resultados ayudan a explicar una gran parte del proceso órgano-específico encontrado en las metástasis, dado que muestra una dirección preexistente en el tumor primario, los resultados no permiten explicar la diversidad en la progresión y la existencia de microinvasiones atípicas en el cáncer. Por tal motivo, conociendo la direccionalidad del microambiente inflamatorio sobre el comportamiento del tumor, demostrado líneas arriba, es que nuestro grupo recientemente encontró que la expresión de receptores de quimiocinas en estado basal, como ha sido evaluado hasta el momento, puede ser modificado dependiendo del tipo de microambiente inflamatorio. Para ello utilizamos la línea celular humana MCF-7, con características de poco metastásica, considerada bien diferenciada histopatológicamente, y que tiene una expresión basal de receptores de quimiocinas muy baja (5). Luego de estimular la línea celular con diversos estímulos inflamatorios in vitro el patrón basal cambio considerablemente de manera selectiva y dependiente al estímulo utilizado, incrementando de manera variable diferentes receptores de quimiocinas significativamente (8). Estos hallazgos muestran que en diferentes momentos del desarrollo tumoral, las células dependiendo del estímulo inflamatorio podrán expresar receptores diferentes que podrían explicar las diferentes metástasis a diferentes órganos frecuentes o no que produzcan el ligando apropiado.
De esta manera, la red de citocinas y quimiocinas existentes en el microambiente tumoral, pueden dirigir el comportamiento del tumor activando $\mathrm{y} / \mathrm{o}$ silenciando diferentes genes pro o anti-tumorales.

Nosotros sugerimos nuevamente, que un balance de esta red de diversos estímulos guiados enteramente por la respuesta global y local del hospedero, dirigirán la evolución de la enfermedad.

\section{CÉLULAS TRONCALES CANCEROSAS Y EL MICROAMBIENTE TUMORAL}

El origen de la diversidad en las metástasis también ha sido atribuido a células troncales cancerosas (CSC) quienes han sido identificadas en tumores sólidos incluyendo el cáncer de mama [36], tumores cerebrales [37-39] y cáncer de colon [40].

De manera similar a sus contrapartes en leucemia, las CSCs en los tumores sólidos, están definidas funcionalmente por una capacidad de iniciar neoplasias y poseen fenotípicamente combinaciones específicas de marcadores de superficie. Las CSCs pueden autorenovarse y diferenciar in vivo, regenerando un tumor heterogéneo después de una implantación en ratones inmunodeficientes, donde células no tumorogénicas obtenidas del tumor original no pueden reproducir un tumor secundario (41-43). Por ejemplo, cerca de 200 células con marcadores $\mathrm{CD}_{4} 4^{+} \mathrm{CD} 24^{- \text {/low }} \mathrm{Lin}^{-}$aisladas de un derrame pleural en pacientes con cáncer de mama fueron capaces de formar un tumor en ratones NOD/SCID, mientras que 20,000 células CD44 CD24+ fallaron en formarlo [36]. Sin embargo, no se ha podido generar un tumor a partir de una sola CSC, lo que es diferente de la capacidad de células troncales mamarias normales que pueden regenerar una glándula mamaria completa [44]. Debido a la capacidad tumorogénica única de las CSC es que se puede tener la hipótesis de que podrían ser las responsables para la generación de metástasis distantes [45-47]. Los tumores primarios podrían tener varios tipos de CSC con propiedades únicas de adaptación en órganos particulares. De alguna manera estas células adquirirían la capacidad metastásica que incrementaría su diversidad por alteraciones genéticas y epigenéticas al azar. Por ejemplo, eventos oncogénicos en las células troncales o progenitoras mamarias podría resultar en subsets de CSCs. Por otro lado, las CSCs podrían adquirir las propiedades metastásicas órganoespecíficas ya en el órgano blanco. La plasticidad y capacidad de diferenciación multilinaje de las CSCs pueden facilitar tales transiciones.

El largo tiempo de latencia de las micrometástasis puede reflejar la gradual adaptación de las CSCs en diferentes microambientes de órganos blanco, un proceso que nuevamente se vería influenciado por estímulos externos tales como inflamación e hipoxia. La interacción entre el tumor y el microambiente podría ocurrir una vez que las células tumorales llegan a su blanco, sin embargo la existencia de "nichos pre-metastásicos" (PMN) reportados recientemente, desafía esta afirmación [48]. Kaplan et al., demostró que factores secretados por tumores primarios de melanoma y cáncer pulmonar, movilizaban células progenitoras de médula ósea hacia órganos donde posteriormente llegaban células metastásicas [48]. Estos 
PMN dictarían patrones de metástasis, o especificidad organotrópica, donde también estarían involucradas moléculas ya descritas anteriormente para favorecer la invasión [49].

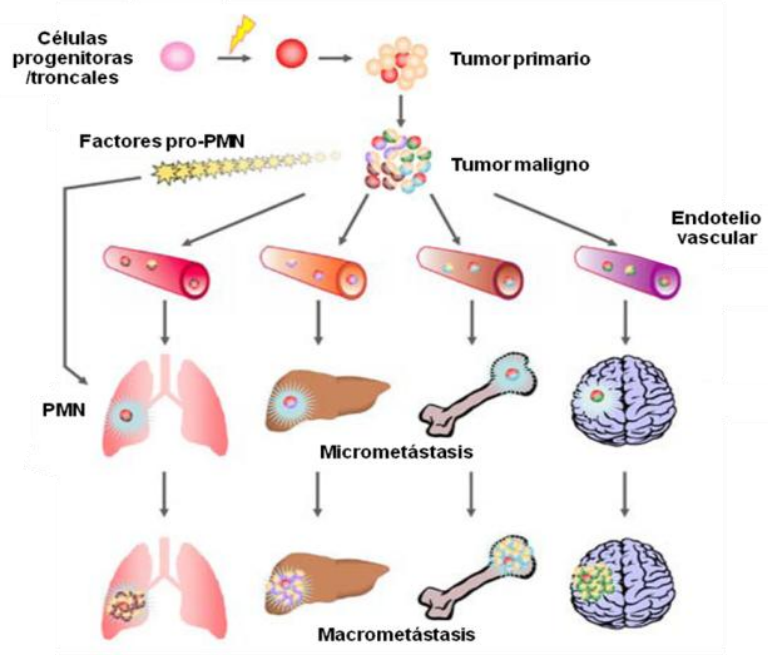

Figura 2. CSC de cáncer de mama son derivadas de transformaciones oncogénicas de troncales normales mamarias y progenitoras. Una o varias CSCs dan heterogeneidad al tumor primario donde el ambiente puede generar programas metastásicos órgano específicos 0 simplemente adquirir capacidades invasivas. Células tumorales diseminadas, incluyendo CSCs metastásicas, son transportadas por sangre a los órganos blanco específicos dependiendo de diferentes sets particulares de moléculas como receptores de quimiocinas que guian el "homing metastásico". La llegada de CSCs a nichos pre-metastásicos

Estos datos indican una amplia comunicación constante entre el órgano blanco y el tumor primario previa a la invasión (Figura 2). De esta manera podemos especular que también el microambiente del tumor primario dictaría la liberación de factores que potenciarían o no la formación de PMNs y que luego de la llegada a estos por las células tumorales, el microambiente local del órgano invadido sería modificado a un "nicho maduro" (MMN). La comprensión de la generación, evolución del PMN y el MMN, y su rol en dar soporte a la metástasis órgano específica puede dar nuevas perspectivas para el desarrollo de nuevas terapias y medidas de pronóstico en el cáncer.

\section{PERSPECTIVAS FUTURAS}

Es evidente la gran cantidad de información y estudios que se realizan para entender la biología y comportamiento de la célula cancerosa en los diferentes tipos de cáncer, pero este hecho se complica aún más cuando se demuestra que "el fondo inmune" de cada persona constituye una variable central en el progreso de la enfermedad. Estos resultados son coherentes con la baja eficacia de los tratamientos convencionales que se basan en destruir el tumor sin una evaluación integral del paciente con cáncer. Tratamientos basados en protocolos que son utilizados de acuerdo a estudios epidemiológicos de mejora en la sobrevida y que se utilizan de igual forma a todo paciente con "el mismo" tipo de tumor histológicamente determinado, sin tomar en cuenta que la progresión será diferente en cada persona. Es también un hecho que el lector podrá pensar que un estudio del microambiente tumoral es complicado y no está al alcance de muchos centros hospitalarios latinoamericanos; pero esa afirmación refleja la falta de una adecuada comprensión integral del proceso que parte de una actividad básica como es la de conocer bien la "historia inmune" del paciente. Refleja también la falta de políticas adecuadas de comunicación con centros especializados en diferentes partes del mundo que gustosamente recibirían muestras de diferente índole; y finalmente refleja la falta de médicos realmente interesados en generar conocimiento desde la investigación con disposición a cambiar paradigmas y solucionar problemas. Conocer el entorno tumoral además de dar una visión más completa de la enfermedad puede brindar mejores directivas en la terapia al usar racionalmente inmunomoduladores usados como adyuvantes. Potenciadores inmunes como BCG, IFN- $\alpha$, IFN-y, IL-2, etc., ó diversos inmunosupresores, podrán cumplir mejor su rol dependiendo de cada caso.

Por otro lado, aunque en los recientes años el rápido progreso ha generado un enorme interés en el estudio del microambiente tumoral y más específicamente en el estudio de la metástasis de cáncer de mama, todavía estamos en la punta del iceberg de un problema muy complicado. Aún existen muchas interrogantes que ponemos a consideración como parte final de este breve trabajo: 1) ¿Cuáles son las condiciones particulares de funcionamiento requeridas para cada metástasis órgano específica?, ¿son diferentes entre los diferentes tipos de cáncer?, ¿existen combinaciones de genes para establecer esas condiciones?, 2) ¿se pueden identificar reguladores maestros del microambiente que dirijan la metástasis?, 3) ¿las señales intracelulares prometástasis, como TGF $\beta$ y NFKB, utilizan diferentes mediadores para promover metástasis órgano específica?, ¿cuáles son los efectores moleculares de estas vías?, 4) ¿podemos mejorar nuestros modelos animales para evaluar requerimientos espacio-temporales de las células cancerosas y sus genes para metástasis y evaluar la interacción con el microambiente?, 5) ¿Cuál es la importancia de las células troncales cancerosas en la progresión de la enfermedad?, ¿el microambiente selecciona variantes de estas células?, ¿son ellas las que llevan una directiva órgano específica de metástasis?, 6) ¿cómo inician y modifican el entorno las células metastásicas en el nuevo órgano?, ¿cómo modifican el nicho inicial para su supervivencia?.

\section{AGRADECIMIENTOS}

Los autores agradecen a todos los organizadores del Encuentro Científico Internacional de Verano 2008 por la organización y aceptación de este trabajo. Felicitamos la iniciativa de reunir a científicos peruanos para compartir e incentivar a la juventud en la investigación. Felicitamos también a la recién formada Academia Peruana de Medicina Molecular quien prontamente se unirá al esfuerzo de unión y cooperación entre médicos peruanos dedicados a la investigación de la medicina molecular y sus ramas afines. 
1. Jemal A, Murray T, Ward E, Samuels A, Tiwari RC, Ghafoor A, et al. Cancer statistics, 2007. CA Cancer J Clin. 2007; 55 1:10-30.

2. S Chambers AF, Groom AC, MacDonald IC. Dissemination and growth of cancer cells in metastatic sites. Nat Rev Cancer 2002;28:563-72

3. Gupta GP, Massague J. Cancer metastasis: building a framework. Cell 2006;127 4:679-95

4. Steeg PS. Tumor metastasis: mechanistic insights and clinical challenges. Nat Med 2006;12 8:895-904

5. Muller A, et al. Involvement of chemokine receptors in breast cancer metastasis. Nature. 2001; 410: 50-6.

6. Martinez Arias A. Epithelial Mesenchymal Interactions in Cancer and Development. Cell, Vol. 105, 425-431, May 18, 2001

7. Lin, E.Y., et al. Colony-stimulating factor 1 promotes progression of mammary tumors to malignancy. J.Exp.Med.2001; 193, 727.

8. Valdivia-Silva J., et al. Differential expression of the chemokine receptors stimuled by inflammatory cytokines in MCF-7 breast tumor cell line: implications in cancer metastasis. Cancer Res. 2008 (en revisión).

9. Allinen M., Beroukhim R., Cai L., Brennan C., Lahti-Domenici J., Huang H., et al. Molecular characterization of the tumor microenvironment in breast cancer. Cancer Res. 2004; 6: 17-32.

10. Ravenswaay Claasen HH, Kluin PM, Fleuren GJ: Tumor infiltrating cells in human cancer. On the possible role of CD16+ macrophages in antitumor cytotoxicity. Lab Invest 1992, 67:166.

11. Rosenberg SA: Progress in human tumour immunology and immunotherapy. Nature 2001, 411:380-384.

12. Urban JL, Shepard HM, Rothstein JL, Sugarman BJ, Schreiber H: Tumor necrosis factor: a potent effector molecule for tumor cell killing by activated macrophages. Proc Natl Acad Sci USA 1986, 83:5233-5237.

13. Pozzi LA, Weiser WY: Human recombinant migration inhibitory factor activates human macrophages to kill tumor cells. Cell Immunol 1992, 145:372-379

14. Coussens LM, Raymond WW, Bergers G, Laig-Webster M, Behrendtsen O, Werb Z, Caughey GH, Hanahan D: Inflammatory mast cells up-regulate angiogenesis during squamous epithelial carcinogenesis. Genes Dev 1999, 13:1382-1397

15. Leek RD, Lewis CE, Whitehouse R, Greenall M, Clarke J, Harris AL: Association of macrophage infiltration with angiogenesis and prognosis in invasive breast carcinoma. Cancer Res 1996, 56:4625-4629.

16. Lee AH, Happerfield LC, Bobrow LG, Millis RR: Angiogenesis and inflammation in invasive carcinoma of the breast. J Clin Pathol 1997, 50:669-673.

17. van Golen KL, Wu ZF, Qiao XT, Bao L, Merajver SD: RhoC GTPase overexpression modulates induction of angiogenic factors in breast cells. Neoplasia 2000, 2:418-425

18. Saji H, Koike M, Yamori T, Saji S, Seiki M, Matsushima K, Toi M: Significant correlation of monocyte chemoattractant protein-1 expression with neovascularization and progression of breast carcinoma. Cancer 2001, 92:1085-1091.

19. Kacinski BM: CSF-1 and its receptor in ovarian, endometrial and breast cancer. Ann Med 1995, 27:79-85.

20. Patterson BC, Sang QA: Angiostatin-converting enzyme activities of human matrilysin (MMP-7) and gelatinase B/type IV collagenase (MMP-9). J Biol Chem 1997, 272:28823-28825

21. Koong AC et al. Candidate genes for hypoxic tumor phenotype. Cancer Res 2000; 60:883-887

22. Zambello F, Trentin L, Facco M, Siviero M, Galvan S, Piazza F, Perin A, Agostini C, Semenzato G. Analysis of TNFreceptor and ligand superfamily molecules in patients with lymphoproliferative disease of granular lymphocytes. Blood 2000; 96:647-654

23. Fajardo LF, Kwan HH, Kowalski J, Prionas SD, Allison AC. Dual role of tumor necrosis factor-a in angiogenesis. Am J Pathol 2000; 140:539-544

24. Lejeune FJ, Ruegg C, Lienard D. Clinical applications of TNF-a in cancer. Current Opin Immunol. 1998; 10:573-580

25. Leek RD, Landers R, Fox SB, Ng F, Harris AL, Lewis CE. Association of tumour necrosis factor alpha and its receptors with thymidine phosphorylase expression in invasive breast carcinoma. $\mathrm{Br} \mathrm{J}$ Cancer. 1998; 77:2246-2251

26. Herrmann F, Helfrich SG, Lindemann A, Schleiermacher E, Huber C, Mertelsmann R. Elevated circulating levels of tumor necrosis factor predict unresponsiveness to treatment with interferon alfa-2b in chronic myelogenous leukemia. J Clin Oncol. 1992; 10:631-634

27. Anasagasti MJ, Olaso E, Calvo F, Mendoza L, Martin JJ, Bidaurrazaga J, Vidal-Vanaclocha F. Interleukin 1 dependent and -independent mouse melanoma metastases. J Natl Cancer Inst. 1997; 89:645-651

28. Selby $\mathrm{P}$ et al. (1987) Tumour necrosis factor in man: clinical and biological observations. $\mathrm{Br} \mathrm{J}$ Cancer 56:803-808

29. Gerard C, Rollins BJ. Chemokines and disease. Nat Immunol. 2001; 2:108-115

30. Negus RPM, Stamp GWH, Hadley J, Balkwill FR. A quantitative assessment of the leukocyte infiltrate in ovarian cancer and its relationship to the expression of CC chemokines. Am J Pathol. 1997; 150:1723-1734

31. Fushimi T, Kojima A, Moore MAS, Crystal RG. Macrophage inflammatory protein 3a transgene attracts dendritic cells to established murine tumors and suppresses tumor growth. J Clin Invest. 2000; 105:13831393

32. Braun SE, Chen K, Foster RG, Kim CH, Hromas R, Kaplan MH, Broxmeyer HE, Cornetta K. The CC chemokine CKb-11/MIP-3b/ELC/Exodus 3 mediates tumor rejection of murine breast cancer cells through NK cells. J Immunol. 2000; 164:4025-4031 
33. Luan J, Shattuck-Brandt R, Hyaghnegahdar H, Owen JD, Strieter R, Burdick M, Nirodi C, Beauchamp D, Johnson KN, Richmond A. Mechanism and biological significance on constitutive expression of MGSA/GRO chemokines in malignant melanoma tumor progression. J Leukoc Biol. 1997; 62:588-597

34. Takamori H, Oades ZG, Hoch OC, Burger M, Schraufstatter IU. Autocrine growth effect of IL-8 and GROalpha on a human pancreatic cancer cell line, Capan-1. Pancreas 2000; 21:52-56

35. Zlotnik A. Chemokines and cancer. Int J Cancer. 2006; 119: 2026-2029

36. Al-Hajj M, Wicha MS, Benito-Hernandez A, Morrison SJ, Clarke MF. From the cover: prospective identification of tumorigenic breast cancer cells. Proc Natl Acad Sci USA 2003;100 7:3983-88.

37. Singh SK, Clarke ID, Terasaki M, Bonn VE, Hawkins C, Squire J, et al. Identification of a cancer stem cell in human brain tumors. Cancer Res 2003;63 18:5821-28.

38. Hemmati HD, Nakano I, Lazareff JA, Masterman-Smith M, Geschwind DH, Bronner-Fraser M, et al. Cancerous stem cells can arise from pediatric brain tumors. Proc Natl Acad Sci USA 2003;100 25:15178-83.

39. Singh SK, Hawkins C, Clarke ID, Squire JA, Bayani J, Hide T, et al. Identification of human brain tumour initiating cells. Nature 2004; 432 7015:396-401.

40. O'Brien CA, Pollett A, Gallinger S, Dick JE. A human colon cancer cell capable of initiating tumour growth in immunodeficient mice. Nature 2007; 445 7123:106-10.

41. Polyak K, Hahn WC. Roots and stems: stem cells in cancer. 2006; 12 3:296-300.

42. Jordan CT, Guzman ML, Noble M. Cancer stem cells. N Engl J Med 2006;355 12:1253-61.

43. Li F, Tiede B, Massague J, Kang Y. Beyond tumorigenesis: cancer stem cells in metastasis. Cell Res 2007; $171: 3-14$.

44. Shackleton M, Vaillant F, Simpson KJ, Stingl J, Smyth GK, Asselin-Labat ML, et al. Generation of a functional mammary gland from a single stem cell. Nature 2006; 439 7072:84-8.

45. Talmadge JE, Wolman SR, Fidler IJ. Evidence for the clonal origin of spontaneous metastases. Science 1982; 217 4557:361-3.

46. Fidler IJ, Talmadge JE. Evidence that intravenously derived murine pulmonary melanoma metastases can originate from the expansion of a single tumor cell. Cancer Res 1986; 46 10: 5167-71.

47. Weigelt B, Peterse JL, van't Veer LJ. Breast cancer metastasis: markers and models. Nat Rev Cancer 2005;5 8:591-602.

48. Kaplan RN, Riba RD, Zacharoulis S, Bramley AH, Vincent L, Costa C, et al. VEGFR1-positive haematopoietic bone marrow progenitors initiate the pre-metastatic niche. Nature 2005;438 7069:820-7.

49. Kaplan RN, Rafii S, Lyden D. Preparing the "soil": the premetastatic niche. Cancer Res 2006;66 23:11089-93 